\title{
A Comparative Study of Thyroid Hormone and Lipid Status of Patient with and without Diabetes in Adults
}

\author{
Hasi Rani Saha ${ }^{1 *}$, Habiba Khan', Bidhan Chandra Sarkar', Shahidul Alam Khan", \\ Niranjan Kumar Sana ${ }^{2}$, Akira Sugawara ${ }^{3}$, Subhagata Choudhury ${ }^{1}$ \\ ${ }^{1}$ Bangladesh Institute of Research \& Rehabilitation in Diabetes, Endocrine and Metabolic Disorders, \\ Dhaka, Bangladesh \\ ${ }^{2}$ Department of Biochemistry and Molecular Biology, University of Rajshahi, Rajshahi, Bangladesh \\ ${ }^{3}$ Graduate School of Medicine, Tohuku University, Sendai, Japan \\ Email: *hasirani85@gmail.com, hk.d906@gmail.com, csbidhan007@gmail.com,drsakhan46@yahoo.com, \\ nksana2003@yahoo.com, akiras2i@med.tohoku.ac.jp, subhagata.bd@gmail.com
}

Received December 14, 2012; revised January 18, 2013; accepted February 18, 2013

Copyright (C) 2013 Hasi Rani Saha et al. This is an open access article distributed under the Creative Commons Attribution License, which permits unrestricted use, distribution, and reproduction in any medium, provided the original work is properly cited.

\begin{abstract}
Introduction: Lipid and thyroid function abnormalities are common in IDDM and NIDDM. Very few studies have addressed this issue in Bangladesh though Bangladeshi population is very much susceptible to patient with diabetes. Aims: To study on lipid profile and thyroid function in IDDM and NIDDM and the effect of glycemic control on it. Patients and Methods: This was a retrospective study carried out in the Dept. of Endocrinology, BIRDEM, Dhaka, Bangladesh during the period of January, 2012 to May, 2012. In this study, population consisted of 120 subjects (Age between 40 - 72 years; and Sex matched) divided into two groups: patient with diabetes 60 subjects (male-30, female-30) and patient without diabetes 60 subjects (male-30, female-30). Plasma glucose, HbA1c and serum lipids were measured by enzymatic method. Thyroid hormones were measured by a Chemiluminescent Micro particle Immunoassay (CMIA). Results: The statistical significance was evaluated by Student's t-test, Correlation-Coefficient test. All Values are given as mean $\pm \mathrm{SD}$. The level of serum TSH in patient with diabetes $(3.43 \pm 2.71)$ was significantly $(\mathrm{p}<0.05)$ increased compared to patient without diabetes subjects $(1.98 \pm 1.72)$. TSH levels were positively correlated with fasting plasma glucose $(r=0.240, p<0.05)$, serum cholesterol $(r=0.290, p<0.020)$ and triglyceride concentration $(r=0.246, p<$ $0.05)$. On the other hand, free $T_{4}$ levels were inversely correlated with postprandial blood glucose $(r=-0.256, p<$ 0.046). Conclusions: It may be concluded that the lipid and thyroid function abnormalities with others socio-demographic and biophysical risk factors were more common in patient with diabetes cases rather than patient without diabetes cases. Therefore, further prospective studies with larger number of patients are required to strengthen the observations of the present study.
\end{abstract}

Keywords: NIDDM; IDDM; Glycosylated Hemoglobin; Lipid Profile; Hypo and Hyperthyroidism

\section{Introduction}

Hypothyroidism and hyperthyroidism are common causes of secondary dyslipidemia [1]. This observation is partly related to the hyperlipidemia known to be present in patients with both primary and secondary hypothyroidism [2]. Several cross-sectional studies have reported increased levels of total cholesterol and low-density lipoprotein (LDL) cholesterol in adults with sub clinical hypothyroidism compared with euthyroid controls [3]. In adults, increasing levels of TSH to be associated with increases in total cholesterol, LDL cholesterol and tri-

\footnotetext{
${ }^{*}$ Corresponding author.
}

glycerides and with decreases in HDL cholesterol [4-6]. In healthy euthyroid adults, both serum TSH and the free $\mathrm{T}_{4}$ value have been found to be positively associated with fasting and post load insulin concentrations and negatively associated with insulin sensitivity [7]. The present investigation is an attempt to study how patient with diabetes affects thyroid function and lipid metabolism in euthyroid individuals and conversely how thyroid diseases could affect glycemic control. Thyroid function is affected in patient with diabetes. Hypothyroidism among patient with diabetes has been frequently encountered $[8,9]$. The major disorders of thyroid gland are hyperthyroidism and hypothyroidism, which have been re- 
ported in over 110 countries of the world with 1.6 billion people at risk $[10,11]$. Defects in carbohydrate metabolizing machinery and consistent efforts of the physiological system to correct the imbalance in carbohydrate metabolism place an overexertion on the endocrine system. Continuing deterioration of endocrine control exacerbates the metabolic disturbances and leads primarily to hyperglycemia $[12,13]$. The adoption of a sedentary lifestyle, the consumption of non-traditional foods, and a genetic predisposition to the disease are thought to be the major underlying causes of the epidemic [14]. The influence of endocrine and non-endocrine organs other than the pancreas on NIDDM is documented. Occasionally, other endocrine disorders such as abnormal thyroid hormone levels are found in diabetes [15]. There is evidence from animal studies that the function of the thyroid gland itself may be altered in diabetes mellitus [16]. $\mathrm{T}_{3}$ production from peripheral $\mathrm{T}_{4}$ mono-denomination is impaired in uncontrolled diabetes mellitus and this impairment is correlated with the impairment of glucose utilization. Similar findings were later observed in another investigation by them on September 1979 and they emphasized that glucose uptake and utilization were important in the regulation of thyroid hormone metabolism by assessing thyroid hormone turn over in diabetic patient [17]. In untreated insulin requiring diabetic patients TSH remained suppressed and $\mathrm{T}_{3}$ and $\mathrm{T}_{4}$ remained low. Measurement of $T_{3}$ and $T_{4}$ are therefore not reliable indicator of thyroid status in the untreated insulin requiring patient with diabetes [18]. Regulation of TSH secretion is altered in NIDDM during decompensate state and normalizes when euglycemia achieved $[19,20]$. Concentration of free rather than total plasma hormones and other workers have observed that in contrast to free $T_{3}$, free $T_{4}$ may be normal or even elevated in other non thyroidal diseases [21, 22].

\section{Materials and Methods}

This was a prospective study carried out in the dept. of Endocrinology, BIRDEM (Bangladesh Institute of Research \& Rehabilitation in Diabetes, Endocrine and Metabolic Disorders)-WHO collaborating center for prevention and control of diabetes. Dhaka, Bangladesh during the period of January, 2012 to May, 2012. In this study population consisted of 120 subjects (Age between 40 - 72 years; and Sex matched) divided into two groups: patient with diabetes 60 subjects (male-30, female-30) and patient without diabetes 60 subjects (male-30, female-30).General health characteristics such as Age, Sex, Smoking status, Family status, Family history, Treatment status and Biophysical characteristics (particularly as related to preference) were investigated by a self-administered questionnaire. All the patients in the patient with diabetes group were confirmed diabetes who previously had fasting plasma glucose levels and plasma glucose at 2 hours of OGTT/After breakfast $>7.0 \mathrm{mmol} / \mathrm{L}$ and $>11.0$ $\mathrm{mmol} / \mathrm{L}, \mathrm{HbAlc}>6.0 \%$ and who were receiving treatment such as insulin, Diet, anti-diabetic drug or physical exercise therapy for NIDDM. In addition, none of the subjects had a history of previous thyroid disease.

\section{Laboratory Procedure}

Consent was taken for each subject and they were requested to fast overnight. Blood samples were collected by venepuncture from patients. The samples were allowed to clot and the Serum separated by centrifugation at $10,000 \mathrm{rpm}$ for 15 minutes at room temperature. Serum samples were stored at $-20^{\circ} \mathrm{C}$ until tested. Blood samples were treated as follows: For Free T4, TSH and lipid estimation $4 \mathrm{ml}$ of blood was taken in a plain test tube and was separated by centrifugation. For glucose estimation $1 \mathrm{ml}$ of blood was placed in a tube containing fluoride. For estimation of HbAlc $1 \mathrm{ml}$ of blood was taken in a separate test tube containing EDTA. The plasma was separated and analyzed within a few hours of collection. Plasma glucose and serum lipids (triglyceride, total cholesterol and HDL cholesterol) were measured in the BIRDEM Biochemistry laboratory, Dhaka by enzymatic method and mentioned briefly. The LDL cholesterol was calculated from observed triglyceride, total cholesterol and HDL cholesterol by using Friedwald's formula (If triglyceride result is below $400 \mathrm{mg} / \mathrm{dL}$ ). If triglyceride result is upon $400 \mathrm{mg} / \mathrm{dL}$ used direct LDL-C measurement method follow. The normal value of serum $\mathrm{FT} 4=(11.0-24.0) \mathrm{pmol} / \mathrm{L}$ and $\mathrm{TSH}=(0.40-5.0)$ $\mathrm{IU} / \mathrm{mL}$. Desirable levels of blood fats are: total cholesterol; below $200 \mathrm{mg} / \mathrm{dL}$, HDL cholesterol; Men: above $40 \mathrm{mg} / \mathrm{dL}$, Women: above $50 \mathrm{mg} / \mathrm{dL}$. LDL cholesterol below $100 \mathrm{mg} / \mathrm{dL}$.

\section{Result}

Information about the demographic characteristics of the study population was shown in Table 1. The mean Age of patient with diabetes subjects were $\left(43.70 \pm 11.17^{\mathrm{NS}}\right.$ years) where as patient without diabetes subjects were (38.61 \pm 13.30 years) (Figure 1). Body mass index were significantly $(\mathrm{p}<0.001)$ increased in patient with diabetes subjects $\left(27.96 \pm 4.35 \mathrm{~kg} / \mathrm{m}^{2}\right)$ compared with that of patient without diabetes subjects $\left(23.97 \pm 3.01 \mathrm{~kg} / \mathrm{m}^{2}\right)$ (Figure 2). We observed that the markedly elevated hypertensive patients in patient with diabetes subjects 22 (36.67\%), whereas the patient without diabetes subjects were $6(10 \%)$. Exsmoker were markedly elevated in patient with diabetes subjects $7(11.67 \%)$ compared with that of patient without diabetes subjects 4 (6.67\%).

Table 2 shows the levels of various biochemical pa- 
Table 1. Comparison of demographic characteristics of patient without diabetes and patient with diabetes subjects.

\begin{tabular}{ccc}
\hline Parameter & Patient without diabetes subjects $(\mathbf{n}=\mathbf{6 0})$ & Patient with diabetes subjects $(\mathbf{n}=\mathbf{6 0})$ \\
\hline Age (years) & $38.61 \pm 13.30$ & $43.70 \pm 11.17^{\mathrm{NS}}$ \\
Sex: male & $50 \%$ & $50 \%$ \\
Female & $50 \%$ & $50 \%$ \\
EX-smoker & $4(6.67 \%)$ & $7(11.67 \%)$ \\
Current smoker & $6(10 \%)$ & $3(5 \%)$ \\
Non smoker & $50(83.33 \%)$ & $46(83.33 \%)$ \\
Tobacco leaf & $6(10 \%)$ & $6(10 \%)^{*}$ \\
Hypertension & $6(10 \%)$ & $22(36.67 \%)^{* * *}$ \\
Diabetes mellitus & $0(0 \%)$ & $60(100 \%)$ \\
Body mass index $\left(\mathrm{kg} / \mathrm{m}^{2}\right)$ & $23.97 \pm 3.01$ & $27.96 \pm 4.35^{* * *}$
\end{tabular}

The statistical significance was evaluated by Student's t-test (paired sample t test). Values are given as mean \pm SD from 60 subjects in patient without diabetes and patient with diabetes subjects. Patient without diabetes subject compared with patient with diabetes subjects, ${ }^{*} \mathrm{p}<0.05,{ }^{* *} \mathrm{p}<0.01,{ }^{* * *} \mathrm{p}<0.001,{ }^{\mathrm{NS}} \mathrm{Not}$ significant.

Table 2. Comparison of biochemical changes in patient without diabetes and patient with diabetes subjects.

\begin{tabular}{ccc}
\hline Parameter & Patient without diabetes subjects $(\mathrm{n}=60)$ & Patient with diabetes subjects $(\mathrm{n}=60)$ \\
\hline Blood glucose fasting $(\mathrm{mmol} / \mathrm{L})$ & $5.16 \pm 0.80$ & $8.24 \pm 2.58^{* * *}$ \\
Postprandial plasma glucose $(\mathrm{mmol} / \mathrm{L})$ & $6.51 \pm 0.95$ & $12.86 \pm 5.25^{* * *}$ \\
HbAlc $(\%)$ & $5.43 \pm 0.39$ & $9.27 \pm 3.53^{* * *}$ \\
Total cholesterol $(\mathrm{mg} / \mathrm{dl})$ & $178.70 \pm 33.81$ & $199.45 \pm 51.34^{* *}$ \\
Triglyceride $(\mathrm{mg} / \mathrm{dl})$ & $155.35 \pm 61.15$ & $195.01 \pm 52.40^{*}$ \\
HDL-C $(\mathrm{mg} / \mathrm{dl})$ & $39.46 \pm 6.88$ & $35.11 \pm 7.71^{*}$ \\
LDL-C $(\mathrm{mg} / \mathrm{dl})$ & $106.71 \pm 23.95$ & $124.25 \pm 38.54^{*}$ \\
TSH $(\mu \mathrm{IU} / \mathrm{ml})$ & $1.98 \pm 1.72$ & $3.43 \pm 2.71^{*}$ \\
$\mathrm{FT}_{4}(\mathrm{Pmol} / \mathrm{L})$ & $15.27 \pm 6.68$ & $16.78 \pm 8.73^{\mathrm{NS}}$ \\
\hline
\end{tabular}

The statistical significance was evaluated by Student's t-test (paired sample $t$ test). Values are given as mean \pm SD from 60 subjects in patient without diabetes and patient with diabetes subjects. Patient without diabetes subject compared with patient with diabetes subjects, ${ }^{*} \mathrm{p}<0.05,{ }^{* *} \mathrm{p}<0.01,{ }^{* * *} \mathrm{p}<0.001,{ }^{\mathrm{NS}} \mathrm{Not}$ significant.

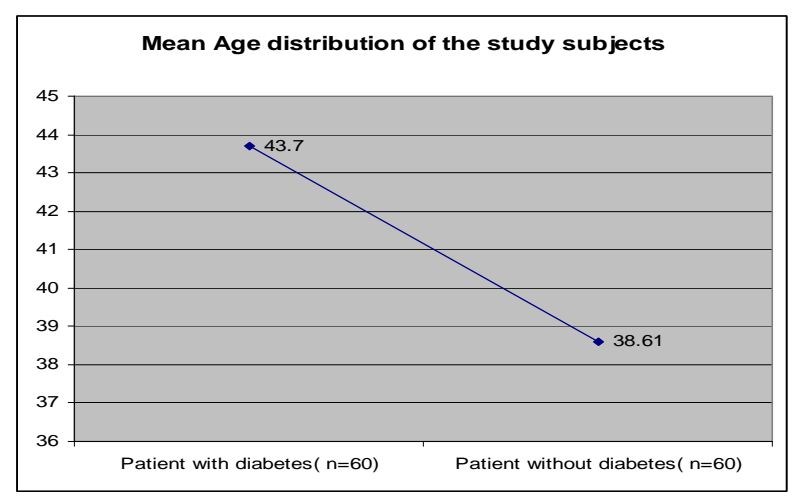

Figure 1. Mean age of the study subjects (patient with diabetes and patient without diabetes).

rameters in patient with diabetes and patient without diabetes subjects. Fasting plasma glucose (FPG) and post-

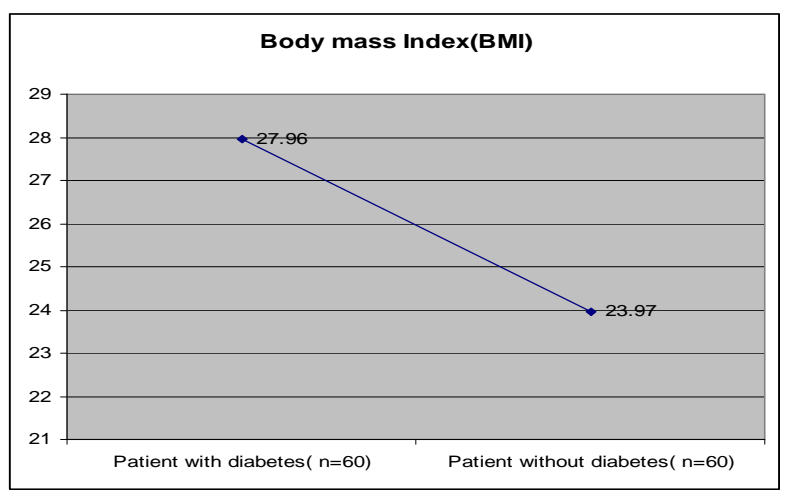

Figure 2. Mean body mass index (BMI) of the study subjects (patient with diabetes and patient without diabetes).

prandial (PPG) level, HbA1c, serum triglyceride, total cholesterol, LDL-C were significantly increased in pa- 
tient with diabetes subjects FPG $(8.24 \pm 2.58, \mathrm{p}<0.001)$, PPG $(12.86 \pm 5.25, \mathrm{p}<0.001)$, HbA1c $(9.27 \pm 3.53, \mathrm{p}<$ $0.001)$, total cholesterol $(199.45 \pm 51.34, \mathrm{p}<0.01)$, triglyceride $(195.01 \pm 52.40, \mathrm{p}<0.05)$, LDL $(124.25 \pm$ $38.54, \mathrm{p}<0.05)$ compared with that of patient without diabetes subjects $(5.16 \pm 0.80,6.51 \pm 0.95,5.43 \pm 0.39$, $155.35 \pm 61.15,178.70 \pm 33.81,106.71 \pm 23.95)$ respectively, and HDL-C levels were significantly $(\mathrm{p}<0.05)$ decreased in patient with diabetes subjects $(35.11 \pm 7.71$, $\mathrm{p}<0.05)$ when compared with that of patient without diabetes subjects ( $39.46 \pm 6.88)$.

Table 2 illustrates the levels of serum thyroid hormones in patient with diabetes and patient without diabetes subjects. The level of serum TSH was increased significantly $(p<0.05)$ in patient with diabetes subjects $(3.43 \pm 2.71)$ compared with that of patient without diabetes subjects $(1.98 \pm 1.72)$ (Figure 3). But $\mathrm{FT}_{4}$ did not differ significantly in patient with diabetes subjects $(16.78 \pm 8.73)$ compared with that of patient without diabetes subjects $(15.27 \pm 6.68)$.

Table 3 shows the distribution of patient with diabetes and patient without diabetes subjects with high, low, and euthyroid thyroid hormone levels. Total 60 patient with diabetes subjects studied, among them 10 (16.67\%) were thyroid dysfunction, whereas $2(3.33 \%)$ were sub clinical hypothyroidism, 4 (6.67\%) were overt hypothyroidism, 3 (5\%) were sub clinical hyperthyroidism and 1 (1.67\%) was overt hyperthyroidism. The prevalence rate of thyroid dysfunction was significantly $(\mathrm{p}<0.05)$ higher in patient with diabetes subjects $10(16.67 \%)$ than in patient without diabetes subjects 7 (11.66\%) (Figure 4).

Table 4 shows, serum TSH values were positively correlated with triglyceride $(\mathrm{r}=0.240, \mathrm{p}<0.05)$ and total cholesterol $(r=0.0 .290, p<0.020)$. On the other hand, free T4 values were inversely correlated with postprandial plasma glucose $(r=-0.259, \mathrm{p}<0.046)$, total cholesterol $(\mathrm{r}=-0.316, \mathrm{p}<0.011)$ and HDL-C $(\mathrm{r}=-0.329, \mathrm{p}<$ $0.051)$.

Table 5 shows, the total 120 subjects (patient with diabetes $=60$ and patient without diabetes $=60$ ) studied among them secondary dyslipidemia were in patient with diabetes cases $6.66 \%$ and in patient without diabetes cases $1.66 \%$. So it was clear that the prevalence rate of secondary dyslipidemia was significantly higher in patient with diabetes subjects $5(8.33 \%, \mathrm{p}<0.05)$ than in patient without diabetes subjects $1(1.66 \%)$ (Figure 5).

\section{Discussion}

Diabetes mellitus is an important health problem affecting major populations worldwide. It is found that diabetic mellitus may be associated with altered thyroid functions. But this phenomenon has been observed mainly in IDDM and NIDDM patients. In Bangladesh a substantial

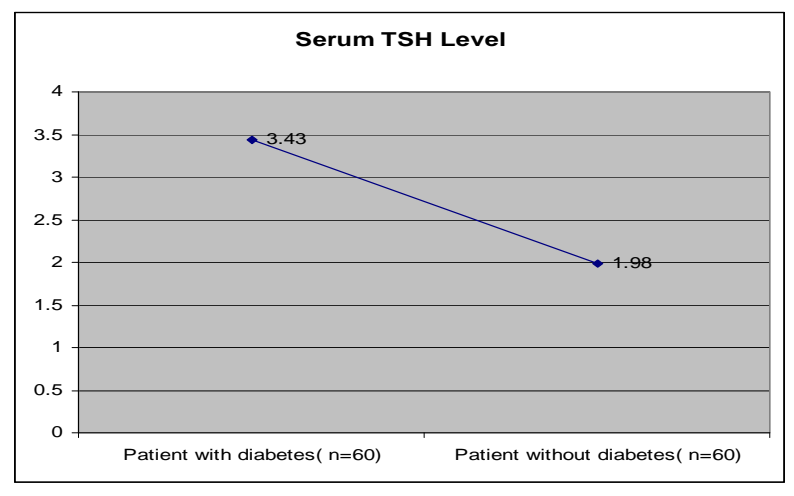

Figure 3. Comparison of thyroid dysfunction of the study subjects (patient with diabetes and patient without diabetes).

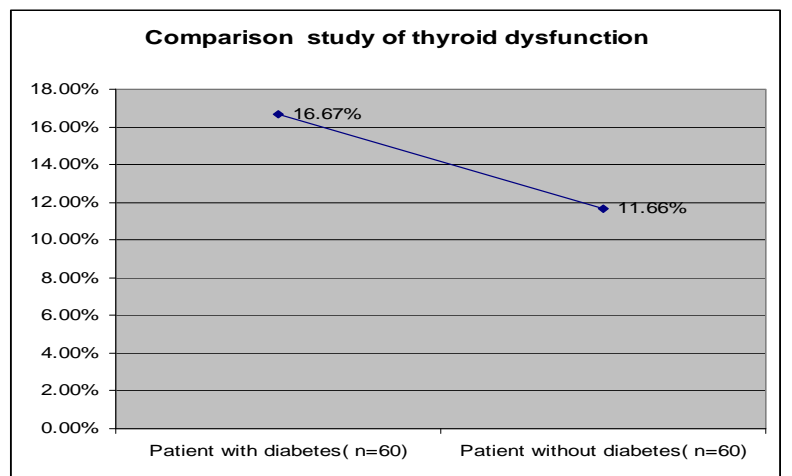

Figure 4. Comparison of thyroid dysfunction of the study subjects (patient with diabetes and patient with diabetes).

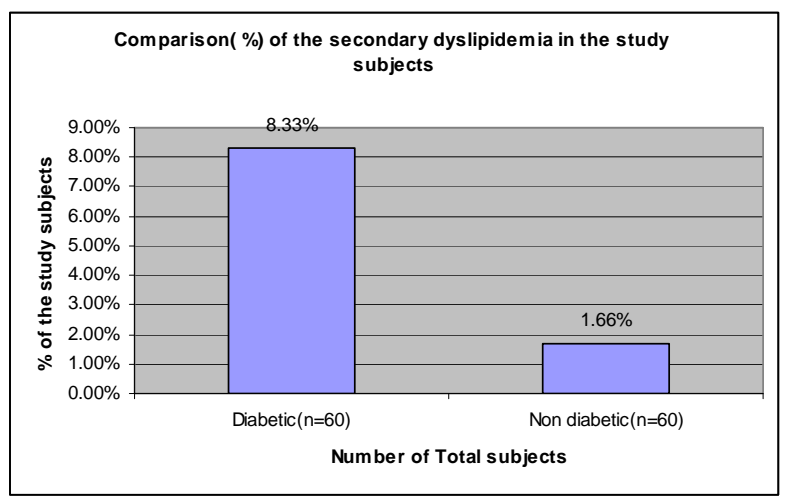

Figure 5. Comparison study of the secondary dyslipidemia of study subjects (diabetic and non diabetic).

number of young patient with diabetes do not show typical characteristics of either IDDM or NIDDM. Three studies have previously been performed at BIRDEM on thyroid functions and alteration of their thyroid function has been found. For a more conclusive comment the better indicators of thyroid dysfunction, free $T_{3}$, free $T_{4}$ are necessary. It is also important to explore the thyroid autoimmunity and morphological changes for better understanding of thyroid dysfunction in these subjects. The 
Table 3. The distribution of subjects with high, low, or euthyroid thyroid hormone levels in patient without diabetes and patient with diabetes subjects.

\begin{tabular}{ccccccc}
\hline \multirow{2}{*}{ Dysfunction } & \multicolumn{2}{c}{ Patient without diabetes subjects $(\mathrm{n}=60)$} & \multicolumn{2}{c}{ Patient with diabetes patients $(\mathrm{n}=60)$} \\
\cline { 2 - 7 } & Total & Male & Female & Total & Male & Female \\
\hline Sub clinical hypothyroidism & $0(0 \%)$ & $0(0 \%)$ & $0(0 \%)$ & $2(3.33 \%)$ & $0(0 \%)$ & $2(3.33 \%)$ \\
Overt hypothyroidism & $4(6.66 \%)$ & $3(5 \%)$ & $1(1.66 \%)$ & $4(6.67 \%)$ & $0(0 \%)$ & $4(6.67 \%)^{*}$ \\
Sub clinical hyperthyroidism & $1(1.66 \%)$ & $0(0 \%)$ & $1(1.66 \%)$ & $3(5 \%)$ & $2(3.33 \%)$ & $1(1.67 \%)$ \\
Overt hyperthyroidism & $2(3.33 \%)$ & $2(3.33 \%)$ & $0(0 \%)$ & $1(1.67 \%)$ & $1(1.67 \%)$ & $0(0 \%)$ \\
Total & $7(11.66 \%)$ & $5(8.33 \%)$ & $2(3.33 \%)$ & $10(16.67 \%)$ & $3(5 \%)$ & $7(11.67 \%)$ \\
\hline
\end{tabular}

$\mathrm{n}=$ number of individuals. The statistical significance was evaluated by Student's t-test (paired sample t test). Values are given as mean \pm SD from 60 subjects in patient without diabetes and patient with diabetes subjects. Patient without diabetes subject compared with patient with diabetes subjects, ${ }_{* * *}^{*}<0.05,{ }^{* *} \mathrm{p}<0.01$, ${ }^{* * *} \mathrm{p}<0.001,{ }^{\mathrm{NS}}$ Not significant).

Table 4. Correlation of serum $\mathrm{FT}_{4}$, TSH with cholesterol, triglyceride, HDL, LDL, Fasting blood glucose, postprandial plasma glucose (PPG) and HbA1c in the study subjects (patients with diabetes individuals).

\begin{tabular}{|c|c|c|c|c|}
\hline \multirow{2}{*}{ Parameter } & \multicolumn{2}{|c|}{$\mathbf{F T}_{4}$} & \multicolumn{2}{|c|}{ TSH } \\
\hline & $\mathbf{r}$ & $\mathbf{p}$ & $\mathbf{r}$ & $\mathbf{p}$ \\
\hline FBS & -0.171 & 0.179 & $0.240^{*}$ & 0.05 \\
\hline PPG & $-0.256^{*}$ & 0.046 & 0.130 & 0.359 \\
\hline $\mathrm{HbAlc}$ & 0.046 & 0.760 & 0.064 & 0.640 \\
\hline Cholesterol & $-0.316^{* *}$ & 0.011 & $0.290^{*}$ & 0.020 \\
\hline Triglyceride & -0.229 & 0.06 & $0.246^{*}$ & 0.05 \\
\hline HDL & $-0.329^{*}$ & 0.051 & 0.091 & 0.459 \\
\hline LDL & -0.190 & 0.138 & 0.205 & 0.101 \\
\hline
\end{tabular}

The statistical significance was evaluated by Student's t-test (paired sample t test). Values are given as mean \pm SD from 60 subjects in patient without diabetes and patient with diabetes subjects. Patient without diabetes subject compared with patient with diabetes subjects, ${ }^{*} \mathrm{p}<0.05,{ }^{* *} \mathrm{p}<0.01,{ }^{* * *} \mathrm{p}<0.001,{ }^{\mathrm{NS}} \mathrm{Not}$ significant.

Table 5. According to the distribution of subjects with high and low level of lipid profile (total cholesterol, HDL cholesterol, LDL cholesterol and triglyceride), in patient without diabetes and patient with diabetes subjects.

\begin{tabular}{|c|c|c|c|c|c|c|}
\hline \multicolumn{7}{|c|}{ Study group } \\
\hline \multirow{2}{*}{ Dysfunction } & \multicolumn{3}{|c|}{ Patient without diabetes subjects $(n=60)$} & \multicolumn{3}{|c|}{ Patient with diabetes subjects $(n=60)$} \\
\hline & Total & Male & Female & Total & Male & Female \\
\hline Secondary dyslipedemia & $1(1.66 \%)$ & $0(0 \%)$ & $1(1.66 \%)$ & $5(8.33 \%)$ & $3(5 \%)$ & $2(3.33 \%)$ \\
\hline Total $(\%)$ & $1(1.66 \%)$ & $0(0 \%)$ & $1(1.66 \%)$ & $5(8.33 \%)$ & $3(5 \%)$ & $2(3.33 \%)$ \\
\hline
\end{tabular}

$\mathrm{n}=$ number of individuals; $\%=$ number of percentage.

presence of both high and low levels of thyroid hormones in diabetics in this study may also be due to modified TRH synthesis and release and may depend on the glycemic status of the with diabetes studied. Glycemic status is influenced by insulin, which is known to modulate TRH and TSH levels [23]. This finding is probably associated with the higher prevalence of obesity recorded in female patient with diabetes. In theory, treating patient with diabetes should be simple: just prevent hyperglycemia from hypoglycemia to cause coma. In practice, it does not work that way. Glucose fluctuations occur all the time. One way to assess the mean levels is to monitor the HbAlc, which gives the average blood glucose level of the preceding $2-3$ months. In uncontrolled or poorly controlled diabetes there is an increased glycosylation of a number of proteins, including hemoglobin and a-crys- 
talline of the lenses. HbA1c was found to increase in patients with diabetes to approximately $16 \%$, and the amount of increase was directly proportional to the fasting blood glucose level. During patient with diabetes, the excess glucose present in blood reacts with hemoglobin $[24,25]$. In the present study, we noticed a marked increase in HbA1c levels in diabetic patients, which could be due to excessive glycosylation of hemoglobin [26].

\section{Conclusion}

In Comparison of demographic characteristics of without diabetes and with diabetes subjects we found that age, BMI, Hypertension and smoking habit were significantly higher with diabetes cases than without diabetes cases. Serum TSH levels were significantly elevated with diabetes cases when compared to the without diabetes cases. With diabetes cases, increases the level of serum total cholesterol, triglyceride and LDL-cholesterol and decreases in HDL cholesterol levels were significantly higher than without diabetes cases. So, finally our findings demonstrate that detection of abnormal thyroid hormone levels in addition to other biochemical variables (lipid profile) in the early stage of diabetes will help patients improve their health and reduce their morbidity rate.

\section{Acknowledgements}

The authors gratefully acknowledge the research facilities provided in the Department of Clinical Endocrinology Laboratory ,BIRDEM, Dhaka, Bangladesh specially by Professor Dr. Subhagata Choudhury, Professor of Biochemistry and Director, Laboratory services, Dr. Shahidul Alam Khan, Chief Research Officer and Head, Dept. of Endocrinology, BIRDEM helped the collect data, plan the study and also Dr. Niranjan Kumar Sana, Professor, Department of Biochemistry and Molecular Biology, University of Rajshahi, contributed to writing the paper, and helped with the discussion section.

\section{REFERENCES}

[1] C. V. Rizos, M. S. Elisaf and E. N. Liberopoulos, "Effects of Thyroid Dysfunction on Lipid Profile," Open Cardiovascular Medicine Journal, Vol. 5, 2011, pp. 7684. doi:10.2174/1874192401105010076

[2] T. O'Brien, S. F. Dinneen, P. C. O'Brien and P. J. Palumbo, "Hyperlipidemia in Patients with Primary and Secondary Hypothyroidism," Mayo Clinic Proceedings, Vol. 68, No. 9, 1993, pp. 860-866. doi:10.1016/S0025-6196(12)60694-6

[3] J. P. Walsh, A. P. Bremner, M. K. Bulsara, P. O'Leary, P. J. Leedman, P. Feddema and V. Michelangeli, "Thyroid Dysfunction and Serum Lipids: A Community-Based Study," Clinical Endocrinology, Vol. 63, No. 6, 2005, pp. 670-675. doi:10.1111/j.1365-2265.2005.02399.x
[4] D. Pallas, D. A. Koutras, P. Adamopoulos, P. Marafelia, A. Souvatzoglou, G. Piperingos and S. D. Moulopoulos, "Increased Mean Serum Thyrotropin in Apparently Euthyroid Hypercholesterolemic Patients: Does It Mean Occult Hypothyroidism?" Journal of Endocrinological Investigation, Vol. 14, No. 9, 1991, pp. 743-746.

[5] B. O. Asvold, L. J. Vatten, T. I. L. Nilsen and T. Bjoro, "The Association between TSH within the Reference Range and Serum Lipid Concentrations in a PopulationBased Study. The HUNT Study," European Journal of Endocrinology, Vol. 156, 2007, pp. 181-186. doi:10.1530/eje.1.02333

[6] S. J. Bakker, J. C. ter Maaten, C. Popp-Snijders, J. P. Slaets, R. J. Heine and R. O. Gans, "The Relationship between Thyrotropin and Low Density Lipoprotein Cholesterol Is Modified by Insulin Sensitivity in Healthy Euthyroid Subjects," Journal of Clinical Endocrinology \& Metabolism, Vol. 86, No. 3, 2001, pp. 1206-1211. doi:10.1210/jc.86.3.1206

[7] J.-M. Fernandez-Real, A. Lopez-Bermejo, A. Castro, R. Casamitjana and W. Ricart, "Thyroid Function Is Intrinsically Linked to Insulin Sensitivity and EndotheliumDependent Vasodilation in Healthy Euthyroid Subjects," Journal of Clinical Endocrinology \& Metabolism, Vol. 91, No. 9, 2006, pp. 3337-3343. doi:10.1210/jc.2006-0841

[8] S. Proces, E. Delgrange, T. V. Vander Borght, J. Jamart and J. E. Donckier, "Minor Alterations in Thyroid Function Tests Associated with Diabetes Mellitus and Obesity in Outpatients without Known Thyroid Illness," Acta Clinica Belgica, Vol. 56, No. 2, 2001, pp. 86-90.

[9] A. M. Michalek, M. C. Mahoney and D. Calebaugh, "Hypothyroidism and Diabetes Mellitus in an American-Indian Population," Journal of Family Practice, Vol. 49, No. 7, 2000, pp. 638-640.

[10] M. Nakazono, M. Kudo, T. Baba, H. Kikuchi and K. Takebe, "Thyroid Abnormalities in Diabetes Mellitus," Tohoku Journal of Experimental Medicine, Vol. 141, 1983, pp. 275-281. doi:10.1620/tjem.141.Suppl_275

[11] A. Khan, M. M. A. Khan and S. Akhter, "Thyroid Disorders, Etiology and Prevalence," Journal of Medical Sciences, Vol. 2, No. 2, 2002, pp. 89-94. doi:10.3923/jms.2002.89.94

[12] G. Saravanan and L. Pari, "Effect of an Herbal Drug, Cogent $\mathrm{db}$ on Plasma and Tissue Glycoproteins in Alloxan-Induced Diabetic Rats," Research Journal of Medicinal Plant, Vol. 1, No. 3, 2007, pp. 83-91. doi:10.3923/rjmp.2007.83.91

[13] A. Bobb, D. Gale, S. Manmohan, A. Mohammed, F. Seetahal, P. Small and K. Mungrue, "The Impact of the Chronic Disease Assistance Plan (CDAP) on the Control of Type 2 Diabetes in Trinidad," Diabetes Research and Clinical Practice, Vol. 80, No. 3, 2008, pp. 360-364. doi:10.1016/j.diabres.2007.11.010

[14] S. Wild, G. Roglic, A. Green, R. Sicree and H. King, "Global Prevalence of Diabetes: Estimates for the Year 2000 and Projections for 2030," Diabetes Care, Vol. 27, No. 5, 2004, pp. 1047-1053. doi: $10.2337 /$ diacare.27.5.1047

[15] P. Perros, R. McCrimmon, G. Shaw and B. Frier, "Fre- 
quency of Thyroid Dysfunction in Diabetic Patients: Value of Annual Screening," Diabetic Medicine, Vol. 12, No. 7, 1995, pp. 622-627. doi:10.1111/j.1464-5491.1995.tb00553.x

[16] N. Bagchi, T. R. Brown, B. Shilver, S. Lucus and R. E. Mack, "Decreased Thyroidal Response to Thyrotropin in Diabetes Mellitus," Endocrinology, Vol. 109, No. 5, 1981, p. 1428. doi:10.1210/endo-109-5-1428

[17] C. S. Pitman, J. B. Chamber Jr. and V. H. Read, "The Extra Thyroidal Conversion Rate of Thyroxine to $\mathrm{T}_{3}$ in Normal Man," Journal of Clinical Investigation, Vol. 50, No. 6, 1971, pp. 1187-1196. doi:10.1172/JCI106596

[18] J. Saunders, S. E. H. Hall and P. H. Sonksen, "Thyroid Hormone in Insulin Requiring Diabetics before and after Treatment," Diabetologia, Vol. 15, No. 1, 1978, pp. 2932. doi:10.1007/BF01219324

[19] U. M. Kabadi, "Impaired Pituitary Thyrotropin Function in Uncontrolled Type II Diabetes Mellitus: Normalization on Recovery," Journal of Clinical Endocrinology \& Metabolism, Vol. 59, No. 3, 1984, p. 521. doi:10.1210/jcem-59-3-521

[20] N. Bagchi, N. Palaniswami, H. Desai, J. Felicetta and T. R. Brown, "Decreased Thyroidal Response to Thyrotropin in Type II DIABETES Mellitus," Metabolism, Vol. 37, No. 7, 1988, pp. 669-671. doi:10.1016/0026-0495(88)90088-1
[21] J. N. Carter, C. J. Eastman, J. M. Corcoran and L. Lazarus, "Effect of Severe, Chronic Illness on Thyroid Function," The Lancet, Vol. 1, 1976, p. 653.

[22] J. H. Oppenheimer, R. Squet, M. I. Surks and H. Haner, "Binding of Thyroxine by Serum Proteins Evauated by Dialysis and Electrophoretic Techniques, Alteration in Nonthyroidal Illness," Journal of Clinical Investigation, Vol. 42, No. 11, 1963, pp. 1769-1782. doi:10.1172/JCI104862

[23] C. E. Reusch and K. Tomsa, "Serum Fructosamine Concentration in Cats with Overt Hyperthyroidism," Journal of the American Veterinary Medical Association, Vol. 215, 1999, pp. 1297-1330.

[24] F. Gloria-Botthini, E. Antonacci, N. Bottini, A. Ogana, P. Borgiani, G. De Santis and N. Lucarini, "Rh Blood Groups and Diabetic Disorders: Is There an Effect on Glycosylated Hemoglobin Level," Human Biology, Vol. 72, 2000, pp. 287-294.

[25] M. J. Sampson, D. A. Hughes, M. J. Carrier and I. R. Davies, "Status of HbA1c during Acute Hyperglycemia in Type 2 Diabetes," Diabetes Care, Vol. 25, No. 3, 2002, pp. 537-541. doi:10.2337/diacare.25.3.537

[26] L. H. Duntas, "Thyroid Disease and Lipids," Thyroid, Vol. 12, No. 4, 2002, pp. 287-293. doi:10.1089/10507250252949405 